was a small loose fragment on the inner side of the orbital fracture. External appearance of child otherwise healthy. The case presents several points of interest. It adds another to those rare cases in which there has been an escape of cerebro-spinal fluid from the vault of the skull; but I am not aware of an! case in which this fluid formed a pulsating tumour under the scalp. By the accident the child was rendered in somewhat the same condition as if it had had an ordinary meningacele, but with of course the addition of the injury to the bone; but it is probable, I suppose, that if the child had lived the tumour would have been cut off from the cavity of the skull by the union of the fracture, and thus hare been reduced to an innocuous cyst of the scalp. It is to be regretted that, from the objections of the parents, the condition of the brain could not be ascertained; but the history of the case certainly points to a merely expectant treatment. It is remarkable, however, that the convulsions of the last few days of life were all confined to the left side, so that they could hardly have been directly due to the escape of the cerebro-spinal fluid, but were, I suppose, more probably the result of some irritation from the fractured bone, which the escape of this fluid allowed to come in contact with the brain. But considering the length of time since the accident during which there had been no head ssmptoms, and the complications of the case, operative interierence could hardly, I think, have been recommended.

Queen Anne-street, Jny, $193 \%$

CASE OF

\section{INTESTINAL OBSTRUCTION LASTING FORTY-SIX DAYS.}

\section{BX HENRY M. MADGE, M.D.}

Mrs. I-, aged twenty-eight, married, and had two children. Belonged to a heaithy family, and until lately had good health. Was a teetotaler, and for some time had been remarkable for being a large eater, particularly of animal food. Hex youngest child was born on February 27th, 1867. When sir months advanced in her last pregnancy, she had an attack of diarrhoea, and subsequently began to suffer from constipation. About six weels after her confinement, finding the constipation rather troublesome, going sometimes a week without proper relief, she became an out-patient at the Middleser Hospital, and at tended for three months. Iot deriving much beneit, she went to the Homøopathic Hospital in Great Ormond-street. After being under homoopathic treatment for several weeks she gave it up as useless.* During all this time the general health was not very much affected, and she was able to attend to all her household and other duties. Towards the end of August, 1867, she passed several days beyond the time usually occupied by her constipated periods, and became very ill, with sickness, fever, rapid pulse, coated tongue, and great abdominal pain and distension. Several means were employed to overcome the obstruction, and on the twelfth day the bowels were relieved, apparently from the use of enemata of rarious kinds, and large doses of calomel frequently repeated. For two or three days the bowels were relaxed, and were relieved of an immense accumulation of fæces. All the flatulent distension disappeared, and the abdomen passed to the opposite condition of extreme flatness and emptiness. There was no tenderness anjwhere on pressure. All the fever and other unfavourable symptoms gradually left her, and the bowels began to act regularly once a day. The patient soon regained strength, and was able to get about as usual, which she did for nearly a month. It was found, howerer, that she was constantly obliged to take aperients, and she was cautioned against the consequences of not doing so. Partly from neglecting this precaution, and partly, I believe, from some irregularities in diet, she aggain fell into her previous condition of constipation and attendant symptoms. This time, however, the attack lasting longer, many of the symptoms-the pain, sickness, prosiration, itc.- - Fere aggravated. The obstruction gave ray on the fourteenth das, apparently from the * The lexding fegrure us this reatment ameared to be warm-water enemata. use of warm-water enemata, and frequent small doses of sulphate of magnesia. She again made a rapid recovery,indeed, more rapid than before, and was able once more to get about for several weeks, when, unfortunately, after neglecting the state of the bowels, all the old symptoms returned. I did not see her until the sixth day of the obstruction, when the fever, sickness, \&c., were just beginning to show themselves.

The friends, with the view, as they said, of obtaining more permanent relief for the patient, now determined on getting her admitted in to the Middlesex Hospital. She remained in the hospital ten days. The measures that were emplozed, however, failed to overcome the obstruction. She left the hospital abruptly on hearing, or fancying she heard, something about an operation to be performed on her. As the patient and her friends were disposed to regard the case as hopeless, several days elapsed before I was sent for. I found her in a very exhausted state, and in extreme pain, from the almost constant violent twistings and contortions of the intestines above the seat of obstruction. 'The colon was enormonsly distended, and its rolling movements were distinctly marked out on the surface of the abdomen. Opium and pressure considerably relieved some of the symptoms-the intestinal movements, also the pain and restlessness. In other respects, the patient got gradually worse.

Abont the thirty-sixth day of the obstruction, the wasting of body and distension of belly were very great. Measurement at umbilicus, 38 inches; pulse 120, and very feeble; features pinched and care-worn ; intellect clear; tongue deep red, but moist; urine scanty and high-coloured; skin moist and cool ; sickness frequent, but there has been no appearance of fæcal matter; stomach rejects everything in the shape of nourishment; supported chiefly by beef-tea enemata. The chances of prolonging life by means of an operation were fairly and frequently placed before the patient and her friends. The suggestion, however, was always met by firm opposition.

She died on December 31st, the obstruction having lasted forty-six days.

Mr. Newton saw the case with me on several occasions, and assisted in directing the treatment.

Post-mortem examination twenty hours after death.-Only a partial examination was allowed. The body generally was greatly emaciated, and of a dusty-yellowish hue. Measurement of abdomen at umbilicus, 40 inches. On opening the abdominal cavity, the distended intestines started out, and seemed like a series of large bladders. Their coats were highly vascular, but everywhere free from lymph or adhesions. The seat of obstruction was found to be at the upper part of the sigmoid flexure, the portion of intestine immediately above being so immensely distended with soft freces as to hang over, and almost fill up the pelvic cavity. A ligature was placed above and below the seat of stricture, and the part removed. On examining the preparation, it was found that the stricture was due to the cicatrisation of a former ulcer of the mucous membrane-an opinion confirmed by another gentleman, a much better authority than myself.

Remarks.-The few remarks that I shall venture to make on this csae will be-1st. That the history of the case, particularly the sickness coming on late in each attack, and at no time with freal matter, and the early distension of the colon, indicated all alone that the seat of obstruction was low down in the intestinal canal-that is, in or about the sigmoid flexure. This was readily diagnosed during life, and it was on this diagnosis that the recommendation of Amussat's operation of opening the colon was founded. 2nd. That, as other means failed, all that could be done was to adopt Dr. Brinton's plan of giving opium, and lengthening out life by every possible means, in the hope that the obstruction would give way.

Fitzroy-square, June, 1869.

Illyess of the Duchess of Aosta.-The Italian papers state that her Highness has suffered from miliary fever, and that she is, happily, on the way to recorery. L'Imparziale, of Florence, is however astonished that the health of the Princess should be entrusted to men who, though certainly highly distinguished, are nevertbeless principally noted as surgeons; whilst no consultation has been held with any of the eminent phrsicians of whom the Cniversity of Florence is justly proud. 